\title{
Impact of a cereal-based diet on intestinal villi of growing rats
}

\author{
S. M. Vidueiros, I. Fernandez, N. Slobodianik, M. E. Roux and A. Pallaro \\ Department of Nutrition, School of Pharmacy and Biochemistry, University of Buenos Aires, Argentina
}

Malnutrition has an adverse impact on cell-mediated, secretory and humoural immunity, as well as on non-specific host defences. Although generalized malnutrition can affect all aspects of host immunity, the impact is greater on T-cell functions and cell-mediated immunity and smaller on B-cell functions as well as humoural immunity. Effects on secretory immunity are intermediate, mainly affecting IgA B-cells. Recent studies have shown that certain chemokines play an important role in regulating homeostatic lymphocyte recirculation through secondary lymphoid organs. The chemokine thymus-expressed chemokine (TECK) is a chemoattractant involved in the ability of lymphocytes to localize in the gastrointestinal tract ${ }^{(1)}$.

The aim of the present work was to study the effect on B and T lymphocytes as well as the TECK + cell population on the intestinal villi of growing rats after the administration of a cereal-based diet as the only source of protein.

Wistar rats were fed a $65 \mathrm{~g}$ precooked maize protein $/ \mathrm{kg}$ diet for $18 \mathrm{~d}(\mathrm{M})$. An age-matched control group received a stock diet (C). Body weight (BW; g) was determined, ponderal growth rate (PGR;g/d per $100 \mathrm{~g}$ ) was calculated and intestines were removed and processed by the Saint Marie technique. Tissue sections were studied by an indirect immunofluorescence technique. CD5 + T-cells and the subsets $\mathrm{TCR} \alpha \beta+, \mathrm{TCR} \gamma \delta+, \mathrm{CD} 4+, \mathrm{CD} 8 \alpha \alpha+, \mathrm{CD} 8 \alpha \beta+$ in the lamina propria (LP) and intraepithelium (iIEL) and IgA-B + cells in LP were determined (number of cells per thirty fields). Also, the presence of TECK + cell population was assessed.

There were significant differences between the $\mathrm{M}$ and $\mathrm{C}$ groups in BW (44.7 (SD 7.83) v. 149.1 (SD 17.7); $P<0.0001)$ and PGR $(-0.30$ (SD 0.39) v. 5.27 (SD 0.53); $P<0.0001$ ). As shown in the Table, the numbers of IgA+ B-cells in the LP and CD5+ T-cells and CD4+, $\mathrm{CD} 8 \alpha \alpha+, \mathrm{CD} 8 \alpha \beta+, \mathrm{TCR} \alpha \beta+$, and TCR $\gamma \delta+\mathrm{T}$ subpopulations in the LP and iIEL of the gut villi for the M group were significantly decreased $(P<0.001)$.

\begin{tabular}{|c|c|c|c|c|c|c|c|c|c|c|c|c|c|c|}
\hline \multirow{2}{*}{$\begin{array}{l}\text { Phenotye } . . . \\
\text { Group (n 6) }\end{array}$} & \multicolumn{2}{|c|}{$\operatorname{Ig} \mathrm{A} \mathrm{B}+$} & \multicolumn{2}{|c|}{ T CD5+ } & \multicolumn{2}{|c|}{$\mathrm{TCR} \alpha \beta+$} & \multicolumn{2}{|c|}{$\mathrm{TCR} \gamma \delta+$} & \multicolumn{2}{|c|}{$\operatorname{CD} 8 \alpha \alpha+$} & \multicolumn{2}{|c|}{$\mathrm{CD} 8 \alpha \beta+$} & \multicolumn{2}{|c|}{$\mathrm{CD} 4+$} \\
\hline & Mean & SD & Mean & $\mathrm{SD}$ & Mean & SD & Mean & SD & Mean & $\mathrm{SD}$ & Mean & SD & Mean & SD \\
\hline \multicolumn{15}{|l|}{ Gut LP } \\
\hline Maize & 57.5 & 16.5 & $39.3^{*}$ & 13.4 & $35.7 *$ & 7.6 & $49.7 *$ & 15.2 & $46.9^{*}$ & 13.8 & $52.6^{*}$ & 17.6 & $59.5^{*}$ & 20.47 \\
\hline Control & 123.5 & 18.7 & 107.8 & 16.2 & 106.7 & 37.5 & 100.9 & 17.8 & 110.1 & 25.1 & 131.7 & 20.8 & 97.4 & 19.3 \\
\hline \multicolumn{15}{|l|}{ Gut iIEL } \\
\hline Maize & & & $2.2 \dagger$ & 1.6 & $1.6 \dagger$ & 1.4 & $2.8 \dagger$ & 1.3 & $0.4 \dagger$ & 0.6 & $0.4 \dagger$ & 0.7 & $0.5 \dagger$ & 1.1 \\
\hline Control & & & 7.6 & 4.3 & 3.3 & 2.3 & 5.4 & 3.8 & 2.8 & 2.2 & 2.0 & 2.0 & 1.7 & 1.9 \\
\hline
\end{tabular}

Mean values were significantly different from those for corresponding age-matched $\mathrm{C}$ group: $* P<0.0001$

Mean values were significantly different from those for corresponding age-matched $\mathrm{C}$ group: $\dagger 0.03>P>0.001$.

Differences in the size and cellularity of the gut villi and in the distribution of TECK were also observed in the experimental groups. When histological slides were analysed, the $\mathrm{C}$ group showed TECK+ cells in the villi and crypt epithelium, while the M group showed a decreased intensity.

The results show that the intake of a low-quality dietary protein as the only source of protein produces an important disorder in mucosal immunity that could explain the incidence of gastrointestinal infections observed in malnourished children.

1. Kunkel EJ, Campbell JJ, Haraldsen G et al. (2000) J Exp Med 192, 761-767. 